\title{
ALIH FUNGSI LAHAN DAN IMPLIKASINYA TERHADAP EKSISTENSI AGAMA DAN BUDAYA DI BALI
}

\author{
Oleh: \\ Ida Bagus Dharmika \\ gusdharmika@gmail.com \\ Prodi Ilmu Agama dan Kebudayaan Pascasarjana \\ Universitas Hindu Indonesia \\ Denpasar
}

Proses Review 02-25 September, Dinyatakan Lolos 26 September 2019

\begin{abstract}
Socio-cultural conflicts that occur in any community in the world including those in various regions of Indonesia were started by the struggle for the natural resources. If this struggle goes according to the rules of the game that they consider fair, then the conflict would not occur. However, if there would be no effort, then the conflict is difficult to avoid. The struggle for the natural resources (land) that ignores the value of justice, honesty and religious values is a source of conflict that cannot be ignored. The problem of land conversions into many functions in Denpasar City has a great obstacle in realizing and maintaining the source of water for the farmlands in order to keep sustainable and influence the culture and religion (super structure) within the Balinese. The conversion of rice fields to restaurants, shops, roads, settlements, offices has been running very quick. Hence, it causes reductions in water absorption to the ground. The rain water falling from the sky does not 'transit' in the fields, or catchments, the water then directly flows into the sea without ever being used as fresh water, clean water. The issue of land, which has so much changed its function, especially in big cities, influences the culture and religion or the super structure adhered by the Balinese people.
\end{abstract}

Keywords: Land conversion, Culture, Religion, Denpasar

\begin{abstract}
Abstrak
Konflik sosial budaya yang terjadi, baik dalam masyarakat manapun di dunia ini termasuk yang di berbagai daerah Indonesia dimulai oleh perebutan sumber-sumber daya alam. Apabila perebutan ini berjalan sesuai aturan main yang mereka anggap adil, maka konflik tidak terjadi. Namun, jika terjadi sebaliknya, maka konflik sulit dihindarkan. Perebutan sumber daya alam (tanah) yang mengabaikan nilai keadilan, nilai kejujuran dan nilai religius merupakan sumber konflik yang tak bisa diabaikan. Persoalan tanah yang banyak beralih fungsi di Kota Denpasar, menjadi halangan yang sangat besar dalam mewujudkan dan menjaga sumber air sawah agar tetap lestari dan mempengaruhi budaya dan agama (super struktur) yang dianut. Alih fungsi sawah menjadi
\end{abstract}


restauran, pertokoan, jalan, pemukiman, perkantoran yang demikian cepat menyebabkan berkurangnya penyerapan air ke tanah. Air hujan yang turun dari langit tidak 'transit' di sawahsawah, tegalan atau resapan, airnya kemudian langsung mengalir ke laut tanpa pernah kita manfaatkan sebagai air tawar, air bersih. Persoalan tanah yang demikian besarnya beralih fungsi terutama di kota-kota besar nantinya akan mempengaruhi budaya, dan agama (super struktur) yang dianut oleh masyarakat Bali.

Kata Kunci: tanah, budaya dan agama

\section{PENDAHULUAN}

Agama Hindu dalam kitab-kitab sucinya sudah sejak zaman dahulu sangat memperhatikan masalah lingkungan, wawasan kesejagatan, dan menyadari posisinya di alam jagat raya ini. Unsur-unsur yang membangun jagat raya ini sangat diperhatikan oleh umat Hindu, unsur-unsur tersebut adalah Pratiwi (Tanah), Apah (Air), Teja (Api), Bayu (Angin), dan Akasa (Angkasa). Panca Maha Bhuta dibentuk oleh unsur halus yang disebut Panca Tan Matra, terdiri atas, Gandha (bau), Rasa (rasa), Sparsa (sinar), Rupa (rupa), dan Sabda (suara). Unsur-unsur yang merupakan obyek indria ini diharapkan berada dalam suatu struktur yang harmonis (somya). Ajaran inilah yang kemudian memunculkan konsep-konsep yang lebih operasional seperti konsep segaragunung, Tri Hita Karana, Tri Mandala, Tri Angga dan sebagainya.

Di dalam kitab suci weda, seperti yang dinyatakan dalam mantram "Bumi ini adalah ibu kita, kita adalah putra-putrannya" (Atharvaveda XII:1,12), "Bumi adalah ibu, dan langit adalah ayah kita" (Yajurveda XXV:17). "Om Yam Prthivi-parama-tirthamrtaya namah svaha" (Prthivi-Stuti dalam Stuti dan Stava:396), serta "Engkau adalah bumi, air, api dan juga angin, angkasa dan alam sunya yang tertinggi, pun pula yang berwujud dan tak berwujud" (Siva-stava:4). Kutipan-kutipan kitab suci i ini sekaligus menunjukkan bahwa sesungguhnya manusia sangat berhutang kepada jagat raya dan senantiasa harus menghormatinya.

Demikian juga dalam lontar Bhuwana Kosa ada disebutkan: "Ini yang disebut tiga dunia yaitu: tanah, angkasa, sorga yang juga disebut indra loka, dikatakan oleh Batara, yang berwarna merah merupakan manifestasi dari Aghora, yang bernama Aghora ditempatkan oleh Sang Resi di dalam pusar. Ong, Ang aksara sucinya." (Bhuwana Kosa, II.1, Brahma Rahasyam, Dwitiyah Patalah).

Tanah atau Pratiwi tempat manusia hidup dinyatakan sebagai kumpulan semua unsur panca maha bhuta (ikang prethiwi ya patimbunan ing tatwa kabeh), oleh karenanya tanah menempati posisi yang sangat penting. Ketika Bhuta yadnya diadakan (dari tingkatan terkecil sampai yang terbesar) senantiasa digelar disebuah 'natar", dimana langit dan tanah, ayah dan ibu bertemu.

Hubungan manusia dengan tanah juga diumpamakan seperti "kadi manik ring сесupu" . Manusia diumpakan sebagai manik (janin), sedangkan alam sebagai cecupu (rahim). Perumpamaan ini mengandung makna bahwa manusia hidup ditengah-tengah alam, dan alamlah yang memberikan makan kepada manusia, seandainya manusia mengambil makanan tanpa batas dan sembarangan maka alam ini akan hancur dan akhirnnya manusia , budaya dan agamanyapun akan hancur.

Bagi orang Bali (baca Hindu) tanah pada dasarnya mempunyai arti nilai yang sangat tinggi jauh melampaui arti tanah secara harfiahnya. Di atas tanah mereka dilahirkan menjalankan kehidupan dan akhirnya mati, melakukan upacara (Dewa yadnya, Rsi Yadnya, Pitra yadnya, Manusa Yadnya, dan Bhuta yadnya), sehingga tidaklah berlebihan bila orang membuat istilah tanah palekadan yang mempunyai arti sangat mendalam. Di sini upacara ritual dan tanah sangat berhubungan erat. Sebagaimana juga disampaikan Ninian Smart (dalam Agung Paramita, 2018: 40) ada tujuh dimensi setiap agama. Salah satu dimensi yang penting adalah dimensi praktis-ritual.

Dalam konteks ini jelas bahwa, tanah telah 
menjadi pendorong utama dalam seluk beluk kehidupan manusia terutama agama dan budayanya, bahwa manusia Bali merupakan produk permukaan bumi Bali. Namun demikian, dewasa ini perkembangan jumlah penduduk, urbanisasi dan laju pelaksanaan pembangunan mendorong meningkatnya intensitas penggunaan sumber daya lahan. Terbatasnya sumber lahan yang tersedia dan intensitas penggunaan yang semakin tinggi di daerah perkotaan akhir-akhir ini akibatnya lebih lanjut adalah tumbuhnya kecenderungan, merubah atau menggeser pola penggunaan lahan yang telah ada.

Bahkan seperti dikemukakan Suparlan (1999), Giddens (1999) Konflik-konflik sosial budaya yang terjadi dalam masyarakat manapun di dunia ini termasuk yang terjadi di berbagai daerah Indonesia dimulai oleh perebutan sumber-sumber daya. Apabila perebutan ini berjalan sesuai aturan main yang mereka anggap adil, maka konflik tidak terjadi. Namun, jika terjadi hal yang sebaliknya, maka konflik sulit dihindarkan. Jadi, perebutan sumber daya yang mengabaikan nilai keadilan, nilai kejujuran dan nilai religius merupakan sumber konflik yang tak bisa diabaikan.

Luas lahan pertanian cenderung mengalami penurunan dari tahun ke tahun akibat dari meningkatnya kebutuhan lahan untuk pemukiman, pariwisata, dan perkantoran. Penyusutan dari luas lahan pertanian akan dapat menyebabkan menurunnya ekosistem suatu wilayah. Akibat yang tak kalah menariknya adalah semakin meningkatnya perkara yang berkaitan dengan tanah yang memberi tekanan tambahan pada sistem nilai, norma hukum kita yang berhubungan dengan sengketa tanah, dan meningkatnya ketegangan antar keluarga, persaingan, kekerasan, dan bergesernya nilainilai sosial religius warga secara individu dan juga komunitas petani, sekaa, banjar dan seterusnnya.

Organisasi subak sebagai suatu sistem mengalami tekanan luar biasa terhadap menyempitnya lahan pertanian ini. Hilangnya pemilik tanah, hilangnya pengempon (warga pendukung) pura subak, hilangnnya aktivitas budaya, hilangnya makna konsepsi Tri Hita Karana, tersumbatnya aliran air oleh pembangunan rumah, banyaknya sengketa perebutan tanah dsb. Dan kalau organisasi subak ini sudah mengalami tekanan dan menyebabkan organisasi ini kucar-kacir, kebudayaanpun akan pontang panting dan akhirnya nilai-nilai keagamaan akan mengalami kemerosotan; sebuah rantai kehidupan yang tidak bisa dielakkan.

\section{METODE DAN PEMBAHASAN}

\subsection{Filosofi Tanah}

Bagi orang Bali (baca Hindu) tanah pada dasarnya mempunyai arti nilai yang sangat tinggi jauh melampaui arti tanah secara harfiahnya. Di atas tanah mereka dilahirkan ,menjalankan kehidupan dan akhirnya mati, melakukan upacara (Dewa yadnya, Rsi Yadnya, Pitra yadnya, Manusa Yadnya, dan Bhuta yadnya)), sehingga tidaklah berlebihan bila orang membuat istilah tanah palekadan yang mempunyai arti sangat mendalam. Bahwa tanah telah membesarkannya, menyuapinya, memberinya tugas, mengarahkan pikirannya, mempertemukannya dengan kesulitankesulitan. Tanah merasuki tulang dan jaringannya, benak dan jiwanya. Di gununggunung tanah memberikannya otot kaki yang membaja untuk mendaki lereng, di sepanjang pantai otot kaki dibiarkan lemah tatapi sebagai gantinya adalah perkembangan dada dan lengan yang kuat untuk mengendalikan papan dayungnya. Tidaklah berlebihan bahwa tanah Bali telah membentuk kebudayaan Bali yang dimiliki oleh manusia Bali.

Dalam konteks ini jelas bahwa, tanah telah menjadi pendorong utama dalam seluk beluk kehidupan manusia terutama agama dan budayanya, bahwa manusia Bali merupakan produk permukaan bumi Bali.

Rupanya manusia Bali sangat menyadari bahwa mereka adalah produk dari permukaan tanah, ini tidak hanya berarti bahwa dia adalah anak tanah, debu dari debunya, tetapi bahwa tanah dan air telah membesarkannya, menyuapinya, memberinya tugas, mengarahkan pikirannya, mempertamukannya dengan kesulitan-kesulitan yang telah memperkuat badannya dan mempertajam akalnya, dan hal ini juga sebagai sebab terwujudnya kebudayaan 
Bali dan terjadinya variasi kebudayaan yang sangat kaya yang dimilki oleh manusia Bali juga disebabkan oleh keadaan tanah pulau Bali.

Namun demikian, dewasa ini perkembangan jumlah penduduk, urbanisasi dan laju pelaksanaan pembangunan mendorong meningkatnya intensitas penggunaan sumber daya lahan. Terbatasnya sumber lahan yang tersedia dan intensitas penggunaan yang semakin tinggi di daerah perkotaan akhir-akhir ini akibatnya lebih lanjut adalah tumbuhnya kecenderungan, merubah atau menggeser pola penggunaan lahan yang telah ada. Bahkan seperti dikemukakan Suparlan (1999), Giddens (1999) Konflik-konflik sosial budaya yang terjadi dalam masyarakat manapun di dunia ini termasuk yang terjadi di berbagai daerah Indonesia dimulai oleh perebutan sumbersumber daya atau sumber-sumber rezeki. Apabila perebutan ini berjalan sesuai aturan main yang mereka anggap adil, maka konflik tidak terjadi. Namun, jika terjadi hal yang sebaliknya, maka konflik sulit dihindarkan. Jadi, perebutan sumber daya yang mengabaikan nilai keadilan, nilai kejujuran dan nilai religius merupakan sumber konflik yang tak bisa diabaikan.

Luas lahan pertanian cenderung mengalami penurunan dari tahun ke tahun akibat dari meningkatnya kebutuhan lahan untuk pemukiman, pariwisata, dan perkantoran. Penyusutan dari luas lahan pertanian akan dapat menyebabkan menurunnya ekosistem suatu wilayah. Akibat yang tak kalah menariknya adalah semakin meningkatnya perkara yang berkaitan dengan tanah yang memberi tekanan tambahan pada sistem nilai, norma hukum kita yang berhubungan dengan sengketa tanah, dan meningkatnya ketegangan antar keluarga, persaingan, kekerasan, dan bergesernya nilainilai sosial religius warga secara individu dan juga komunitas petani, sekaa, banjar dan seterusnya.

Organisasi subak sebagai suatu sistem mengalami tekanan luar biasa terhadap menyempitnya lahan pertanian ini. Hilangnya pemilik tanah, hilangnya pengempon (warga pendukung) pura subak, hilangnnya aktivitas budaya, hilangnya makna konsepsi Tri Hita Karana, tersumbatnya aliran air oleh pembangunan rumah, banyaknya sengketa perebutan tanah dsb. Dan kalau organisasi subak ini sudah mengalami tekanan dan menyebabkan organisasi ini kucar-kacir, kebudayaanpun akan pontang panting dan akhirnya nilai-nilai keagamaan akan mengalami kemerosotan, sebuah rantai kehidupan yang tidak bisa dielakkan.

Ajaran-ajaran suci agama Hindu yang tersurat dalam kitab-kitab suci telah menjadi pedoman bagi masyarakat Hindu dalam bentindak dan bertingkahlaku untuk senantiasa menghormati perthiwi sebagai kumpulan semua unsur panca maha bhuta, tempat manusia hidup dan mati. Bagi orang Bali tanah pada dasarnya mempunyai arti nilai yang sangat tinggi jauh melampaui arti tanah secara harfiahnya, tanah telah membentuk kebudayaan Bali yang khas, unik dan universal. Bahwa masyarakat dan kebudayaan Bali merupakan produk dari permukaan tanah Bali.

Bagi orang Bali tanah (baca:ruang) pada dasarnya mempunyai arti nilai yang sangat tinggi jauh melampaui arti tanah secara harfiahnya. Di atas tanah mereka dilahirkan menjalankan kehidupan dan akhirnya mati, melakukan upacara (stage a long the life cycle), sehingga tidaklah berlebihan bila orang membuat istilah tanah palekadan yang mempunyai arti sangat mendalam. Bahwa tanah telah membesarkannya, menyuapinya, memberinya tugas, mengarahkan pikirannya, mempertemukannya dengan kesulitankesulitan. Tanah merasuki tulang dan jaringannya, benak dan jiwanya. Di gununggunung tanah memberikannya otot kaki yang membaja untuk mendaki lereng, di sepanjang pantai otot kaki dibiarkan lemah tatapi sebagai gantinya adalah perkembangan dada dan lengan yang kuat untuk mengendalikan papan dayungnya. Tidaklah berlebihan bahwa tanah Bali telah membentuk kebudayaan Bali yang dimiliki oleh manusia Bali.

Kecendrungan lain terhadap penyusutan lahan ini, adalah berkurangnya fleksibelitas dan meningkatnya eklusivitas sementara tekanan pada tanah dan, biasanya harga tanah relatif naik, sehingga menciptakan pelapisan ekonomi dan sosial yang memburuk, pada saat tertentu akan memperburuk kestabilan sosial. Kasus-kasus tentang konflik yang diakibatkan 
oleh perebutan pelaba pura, ketegangan antar warga antar banjar adat memperebutkan tanah setra, lapangan desa adalah kasus kasus yang muncul kepermukaan sebagai akibat dari persoalan tersebut.

Akibat yang tak kalah menariknya adalah semakin meningkatnya perkara yang berkaitan dengan tanah yang memberi tekanan tambahan pada sistem hukum kita yang berhubungan dengan sengketa tanah, dan meningkatnya ketegangan antar keluarga, persaingan, dan beberapa hal kekerasan. Contoh-contoh tentang kasus ini dapat kita baca dan dengar setiap saat di media massa.

Adanya alih fungsi tanah yang tak terkendali, harga tanah yang semakin menggila akan memunculkan berbagai persoalan dan konflik sosial budaya, menurunnya ekosistem suatu wilayah, ketegangan antar keluarga, munculnya berbagai perkara berkaitan dengan tanah, kekerasan, pergeseran nilai-nilai sosial budaya, dan ketidakberumahan/ keterasingan di daerah sendiri, adalah beberapa persoalan yang sudah mulai tampak kepermukaan. Hal ini disebabkan karena agama, budaya sebagai pedoman bertingkahlaku sudah mulai tidak disikapi dengan positif.

\subsection{Konflik}

Bukan surga ekonomi melihat kondisi kian beralihnya kepemilikan tanah dan alih fungsi lahan di Bali, saya jadi ingat buku Sisi Gelap Pulau Dewata karya Geoffrey Robinson. Dalam buku tersebut, Robinson sudah menceritakan bagaimana peliknya urusan tanah bagi orang Bali sejak zaman Kolonial, tepatnya 1920-an. Ketika itu, pajak tanah merupakan salah satu sumber pendapatan utama bagi pemerintah kolonial di Bali. Pajak tanah di Bali bahkan lebih mahal 1,5 hingga 2 kali dibandingkan daerah lain di luar Jawa dan Madura. Bahkan, untuk daerah tertentu, harga tanah dan pajaknya pun lebih mahal dibandingkan di Jawa sekalipun. Pada 1927, pajak tanah dari warga Bali mencapai dua pertiga dari seluruh pendapatan pajak tanah pemerintahan kolonial di luar Jawa dan Madura.

"Angka-angka tersebut menunjukkan bahwa tanah bukanlah surge ekonomi bagi orang Bali melainkan menjadi sumber pajak bagi pemerintah," tulis Robinson. Karena mahalnya pajak, maka petani pemilik terpaksa menjualnya. Tanah pun berpindah kepemilikan ke segelintir orang-orang kaya dan ningrat. Banyak warga Bali menjadi tuna-tanah. Hampir seratus tahun kemudian, kejadian sama berulang. Tanah di Bali makin mahal dan tak terbeli. Bedanya, kepemilikan tanah makin berpusat pada sekelompok pemodal.

Secara lebih spesifik dapat digambarkan bagaimana masyarakat subak Lungatad di Denpasar Utara ini secara massif telah menjual tanahnya, subak Lungatad yang pada tahun 1992 luasnya sebanyak 250 Ha dan pada tahun 2018 ini masih tersisa 52 Ha hampir 80\% tanah sawah telah beralih fungsi. Sebanyak lima informan sempat diwawancarai di tiga subak yaitu, subak Pahaang, subak Beteng Sari dan subak Peninjauan yang merupakan wilayah subak Lungatad di Denpasar Timur memperlihatkan seperti berikut ini. Wayan Gatra (60Th) yang tinggal di jalan Cekomaria, Peguyangan Kangin Denpasar Timur, yang pada tahun 1998 menjual tanah warisan seluas 17 are yang dipergunakan untuk memperbaiki tempat suci (sanggah) sekaligus melakukan upacara ngenteg liggih di sanggah tersebut. Dan sisa hasil jual tanah waris itu dipergunakan untuk berfoya-foya atau dengan istilah sekarang gaya hidup.

Dalam kehidupannya sekarang kehidupannya tidaklah baik. Kehidupan serupa yang diperlihatkan oleh Mangku Bawa 55 tahun yang menjual tanah tegalan sebanyak 30 are dan sawah warisan seluas 10 are. Hasil jualan tanah waris ini dipergunakan untuk memenuhi gaya hidup dan gaya anak kekinian yang juga dinikmati oleh anak mereka. Walaupun Sdr Mangku Bawa sempat membuat sanggah yang rupanya bertujuan hanya untuk menutupi kepada masyarakat sekitarnya bahwa mereka menjual tanah warisan, dan hasilnya hanya untuk memenuhi gaya hidup (beli mobil, bikin rumah, dll) sebagai OKB (Orang Kaya Baru).

Kasus yang sama juga dilakukan oleh Wayan Nadi dengan menjual tanah seluas 40 are dipakai untuk membangun toko, dan usaha membuat batako . usaha ini rupannya hanya sebagai kedok untuk menutup keinginan mereka untuk bergaya hidup mewah, membeli mobil 
dan dianggap hidup happy oleh masyarakat umum, yang sekarang menjadi miskin kembali. Hal yang sama dilakukan oleh Wayan Rapet yang telah menjual sawah warisan seluas 40 are, yang dipakai untuk hidup mewah, walaupun juga dia juga membeli tanah di tempat lain, tapi gaya hidup mewah ini tidak bisa ditinggalkan. Apa yang disampaikan oleh anak dari I Wayan Dana (alm) yang telah menjual tanah warisan seluas 30 are pada saat itu. Semua hasil penjualan tanah saat itu dipergunakan untuk memenuhi gaya hidup mewah dan hanya sedikit yang dipergunakan untuk upacara agama.

Semua data yang telah dipapar di atas, memperlihatkan bahwa masyarakat menjual tanah warisan pada ujungnya adalah untuk memenuhi gaya hidup mewah (beli mobil, Hp, rumah yang bagus dll) yang sifatnya konsumtif yang sifatnya sangat pendek dan samasekali bukan untuk kehidupan jangka panjang. Menjadi OKB hanya sebuah symbol palsu yang diagung-agungkan dan akhirnya menjebak mereka menjadi miskin lagi sekarang . Pada akhirnya semua yang dicita-citakan itu akhirnya sirna setelah dipakai uang dari hasil penjulan tanah warisan tidak lebih dari 5 tahun, memang sangat tragis, hidup miskin lagi itulah nasib mungkin pastu bahwa orang Bali yang beragama Hindu emoh menjual warisan.

\subsection{Strategi}

Walaupun secara kogniif strategi-strategi yang dikembangkan oleh beberapa orang warga masyarakat yang berfikir untuk melestarikan budaya yang dimunculkan oleh keberadaan tanah ini. Masyarakat yang telah terlanjur dan mereka yang memiliki dugaan bahwa mungkin saja mereka melakukan penjualan tanah, maka strategi yang dikembangkan dapat ditafsirkan sebagai berikut.

Tanah yang dijual disekitar daerah Kota Denpasar, karena kena jalur untuk membuat jalan, pembangunan fasilitas pemerintah, karena saluran air yang tidak terkendali dan juga karena kemampuan menggarap tanah tidak dimiliki lagi oleh seorang pemilik tanah, maka strategi yang dikembangkan adalah membeli tanah di daerah lain seperti daerah Petang, Munduk, dan juga kedaerah kabupaten Jembrana yang merupa sawah maupun perkebunan. Tanah yang diperoleh atau ditukar dengan tanah di Kota Denpasar dengan jumlah yang jauh lebih luas dengan tanah asalnya di Kota Denpasar.

Dengan mengadakan ritual di pura maupun di sanggah, pemerajan adalah strategi yang dikembangkan oleh seseorang yang telah menjual tanah sawah maupun tegalan. Ritual yang cukup besar untuk ukuran sanggah maupun merajan adalah kewajiban para pemeluk Hindu di Bali selama dia masih hidup, atau hidupnya akan lengkap apabila dia bisa mengaturkan yadnya di pamrajan maupun sanggah.

Membangun rumah adalah juga strategi yang dikembangkan oleh mereka yang baru jual tanah sawah. Bagi mereka, yang penting ada wujud fisik yang bisa diperlihatkan kepada kalayak setelah sawah mereka terjual. Dalam memenuhi salah satu kebutuhan dasar manusia (sandang, pangan, papan) maka membangun rumah adalah strategi yang dikembangkan oleh mereka yang telah menjual tanah sawah. Rumah adalah kebutuhan dasar dari manusia, terutama bagi masyarakat Bali yang beragama Hindu dikenal adannya tingkatan didalam hidupnya, yaitu brahmacari, grehasta, wanaprasta dan sanyasin.

Setiap tingkatan dalam hidup ini harus dilalui oleh setiap orang, dan ketika seseorang akan menginjak masa grehasta (berumah tangga) maka kebutuhan akan rumah menjadi sangat penting dalam menjalankan hidup berumah tangga. Bagi masyarakat Bali Aga, seperti Tenganan Pegringsingan bagi mereka akan membangun rumah tangga, maka pengantin itu wajib melaporkan diri pada sangkepan desa dan selanjutnya setelah memenuhi ketentuan adat pasangan ini akan mendapatkan kaplingan tanah dan bahan bangunan untuk membangun rumah, bahan bangunan untuk mendirikan rumah diambil dari bahan kayu yang berada di hutan desa tersebut.

\section{PENUTUP}

Hubungan manusia dengan tanah juga diumpamakan seperti "kadi manik ring cecupu". Manusia diumpakan sebagai manik (janin), sedangkan alam sebagai сесири (rahim). Perumpamaan ini mengandung makna bahwa 
manusia hidup ditengah-tengah alam, dan alamlah yang memberikan makan kepada manusia, seandainya manusia mengambil makanan tanpa batas dan sembarangan maka alam ini akan hancur dan akhirnnya manusia, budaya dan agamanya pun akan hancur. Bagi orang Bali (baca Hindu) tanah pada dasarnya mempunyai arti nilai yang sangat tinggi jauh melampaui arti tanah secara harfiahnya.

\section{DAFTAR PUSTAKA}

Agung Paramita, 2018. Bencana, Agama dan Kearifan Lokal. (Jurnal Dharmasmrti Vol. 1 No. 18, Denpasar Jurnal Ilmu Agama dan Kebudayaan Universitas Hindu Indonesia, 2018).

Faisal Kasryno. dkk. 2003. Subak dan Kerta Masa, Kearifan Lokal Mendukung Pertanian Berkelanjutan. Jakarta: YAPADI dan IRF.

Giddens, Anthony. 2003. The Constitution of Society, Teori Strukturasi untuk Analisis Sosial. (penerjemah: Loka Sujono). Pasuruan: Pedati.

Koentjaraningrat. 1988. "Antropologi dan Pembangunan". Pidato Purnakarya Kedinasan. dalam Tanam satu Tumbuh Seribu Koentjaraningrat dan Antropologi di Indonesia. Jakarta: Jurusan Antropologi Fisipol UI. 